\title{
LONG DAY CARE CENTRE IMMUNISATION RATES IN WESTERN SYDNEY
}

Bin Jalaludin and Cissy Chow

Western Sector Public Health Unit

In April 1995 the Western Sector Public Health Unit conducted a postal survey of immunisation status of children aged two to three years attending long day care centres (LDCCs) in greater western Sydney. The results reported here provide baseline immunisation rates for an ongoing immunisation surveillance program.

Changes were introduced to the NSW Public Health Act 1991 in 1992. The Public Health Act now requires parents of all children enrolling in schools, preschools and child-care centres to provide documented evidence of immunisation to school and child-care authorities ${ }^{1}$. Schools and child-care centres are required to maintain immunisation registers which may be used as a surveillance tool for monitoring immunisation status of young children in our community. This is important as children attending schools, preschools and day care centres are at higher risk of contracting communicable diseases including vaccine-preventable diseases $^{23}$. LDCCs provide care for children under school age on a regular full-time or part-time basis, and are required to be open for at least eight hours a day, five days a week and 48 weeks a year.

We did not measure immunisation rates for Haemophilus influenzae type $\mathrm{b}$ (Hib) as this vaccine was added to the childhood immunisation schedule after this study cohort of children were born.

\section{METHODS}

We surveyed all 34 LDCCs in the Wentworth Health Area and all 80 in the Western Sydney Health Area. We excluded family day care centres, occasional child-care centres and preschool kindergarten from this survey.

We sent an initial letter to the directors of the $114 \mathrm{LDCCs}$ in mid-March 1995 to inform them of the survey, and asked them to ensure their immunisation register was updated. Early in April 1995 a questionnaire was sent to all LDCCs. The questionnaire elicited information on name, date of birth, gender and Aboriginality of all two- to three-year-old children, and if and when triple antigen (DTP), Sabin oral polio (OPV) and measles-mumps-rubella (MMR) vaccines had been given.

We entered the data into a database ${ }^{4}$, and used the SAS statistical program for analysis ${ }^{5}$. We interpreted missing immunisation records as 'not immunised'. We calculated immunisation rates in two ways: first, for children at the age of two years (up-to-date immunisation rates), and second, at the time of the survey (when children were aged between two and three years). For the first calculation, children had to have received all the relevant

immunisations and have recorded dates for the fourth DTP, third OPV and MMR. Those without recorded immunisation dates were excluded from this analysis.

\section{RESULTS}

We received completed questionnaires from 95 of 114 long day care centres ( 83 per cent) [ 28 from Wentworth Health Area (82 per cent), and 67 from Western Sydney Health Area (84 per cent)].

A total of 1,092 two- to three-year-old children was enrolled

\begin{tabular}{|c|c|c|c|c|}
\hline \multicolumn{5}{|c|}{$\begin{array}{l}\text { IMMUNISATION RATES FOR DTP, OPV AND MMR IN } \\
\text { WESTERN SYDNEY, LDCC IMMUNISATION SURVEY - APRIL } 1995\end{array}$} \\
\hline two & $\begin{array}{l}\text { mmun } \\
\text { years } \\
\mathrm{N}^{2}\end{array}$ & $\begin{array}{l}\text { rcent } \\
\text { d by } \\
\text { age } \\
\%\end{array}$ & $\begin{array}{l}\text { immur } \\
\text { time of } \\
N\end{array}$ & $\begin{array}{l}\text { rcent } \\
\text { ed at } \\
\text { urvey } \\
\%\end{array}$ \\
\hline DTP (3 doses) & 928 & 94.1 & 1,092 & 95.0 \\
\hline OPV (3 doses) & 930 & 92.4 & 1,092 & 93.6 \\
\hline MMR (1 dose) & 932 & 91.3 & 1,092 & 93.5 \\
\hline DTP (4 doses) & 933 & 77.6 & 1,092 & $83.9^{*}$ \\
\hline $\begin{array}{l}\text { All eight immunisations } \\
\text { (4 DTP, } 3 \text { OPV \& MMR) }\end{array}$ & 911 & 76.2 & 1,092 & $81.7 * *$ \\
\hline
\end{tabular}

1. Immunisation rates calculated after excluding children without recorded immunisation dates.

2. $\mathrm{N}$ is the denominator for both Health Areas combined.

*Immunisation rates by age of two years compared to immunisation rates at time of survey; $p<0.01$.

**Immunisation rates by age of two years compared to immunisation rates at time of survey; $p<0.05$.

in the 95 LDCCs. Only five children were identified as Aboriginal (Aboriginality was not recorded in 53 cases). There were more boys ( 50 per cent) than girls ( 47 per cent) enrolled in LDCCs that completed the questionnaire. The median age of children in the survey was 31.1 months.

As we found no differences in immunisation rates between the two Health Areas, we present results for both Areas combined. By two years of age, more than 90 per cent of children had received three doses of DTP and OPV, and one dose of MMR (Table 2). About 17 per cent fewer children had received four doses of DTP compared to three doses of DTP. Immunisations for all the scheduled childhood immunisations up to the age of 18 months (eight doses of vaccine) were completed by just over 76 per cent of children. There were no gender differences for immunisation rates at the age of two years.

Immunisation rates at the time of the survey for children aged 2-3 years (these rates cover only the children who had received the stated number of immunisations at the time of the survey), for three doses of DTP and OPV, and one dose of MMR were similar to immunisation rates calculated for immunisations received by the age of two years (Table 2). However, immunisation rates for four doses of DTP and all eight immunisations were significantly higher than rates calculated for immunisations received by the age of two years (four doses DTP, $\mathrm{p}<0.001$; all eight vaccines; $\mathrm{p}<0.05$ ).

There were no differences in immunisation rates at the time of the survey between boys and girls for three doses of DTP, three doses of OPV and one dose of MMR. Boys had significantly lower immunisation rates for four doses of DTP (boys: 82 per cent, girls: 86 per cent; $p<0.05$ ) and for all eight doses of vaccine (boys: 79 per cent, girls: 84 per cent; $\mathrm{p}<0.05$ ). These gender differences persisted within the Health Areas, but were not significant. 


\section{DISCUSSION}

In this study of immunisation rates in children aged 2-3 years enrolled in LDCCs in greater western Sydney, the up-to-date immunisation rates at two years of age for three doses of DTP, four doses of DTP, three doses of OPV, one dose of MMR and all eight immunisations were 94 per cent, 78 per cent, 92 per cent, 91 per cent and 76 per cent respectively. There is a precipitous drop in the rate of immunisation with the fourth dose of DTP. Reasons for nonimmunisation with the fourth dose of DTP were not elicited, but need to be examined. Not unexpectedly, immunisation rates at the time of the survey were higher compared to immunisation rates at two years of age.

The National Immunisation Strategy (NIS) ${ }^{6}$ aims to achieve $>90$ per cent coverage of children aged two years for all diseases specified in the childhood immunisation schedule by 2000 . In this survey of LDCCs, NIS targets for three doses of DTP, three doses of OPV and one dose of MMR were achieved, but immunisation rates for four doses of DTP and hence for all eight immunisations were substantially lower than the 2000 target. This is of concern since we would expect children attending LDCCs to have higher immunisation rates than non-attenders?.

Immunisation registers in LDCCs in NSW are used as surveillance tools. However, only about 14 per cent of all children $<4$ years of age in NSW attend $\mathrm{LDCCs}^{8,9}$. The immunisation status of these children may be quite different from children who do not attend LDCCs, and we should be cautious when generalising such results to children who do not attend LDCCs. Preschools may provide an additional source of surveillance information which may complement data from LDCCs.

We presented two sets of immunisation rates (including up-to-date rates) in this study. Whether immunisation rates should be presented as age-appropriate rates (not presented here) or as up-to-date rates is debated ${ }^{10,11}$. There are also views on how age-appropriate immunisation rates should be calculated. Standard definitions for age-appropriate and up-to-date immunisation rates should be developed to allow immunisation rates within and between States and Territories to be compared.

The low rates for four doses of DTP and all eight immunisations at the age of two years indicate that we need to target groups identified to have poor immunisation rates. We need to understand reasons for non-immunisation and delayed immunisation, and instigate innovative programs to ensure that more children - especially high-risk children are immunised, and at the recommended age, to enable us to achieve NIS targets.

\section{ACKNOWLEDGEMENTS}

We thank all the directors and staff of the long day care centres who participated in this study. We also thank Susan DeBrincat-Trapuzzano for data entry, and the NSW Health Department for the SSISS methodology.

1. NSW Immunisation Requirements for school entry from 1994, State Health Publication Number (EB) 92-87, ISBN 0730535975. 2. Klein JO. Infectious diseases and day care. Review of Infectious Diseases 1986; 8(4):521-6.

3. Thacker SB, Addiss DG, Goodman RA et al. Infectious diseases and injuries in child day care. Opportunities for healthier children. Journal of the American Medical Association 1992; 268(13):1720-6.

4. Microsoft Access. Relational database management system for windows, Version 2.0. Microsoft Corporation 1994.

5. SAS Institute Inc. SAS ${ }^{3}$ Procedures Guide, Release 6.03 Edition. Cary, NC: SAS Institute Inc, $1988.441 \mathrm{pp}$.

6. National Immunisation Strategy. Report by the Panel on a National Immunisation Strategy on behalf of the Communicable Diseases Standing Committee. NHMRC April 1993. Commonwealth of Standing Commitralia 1998

7. Hinman AR. Vaccine-preventable diseases and child day care. Review of Infectious Diseases $1986 ; 8(4): 573-83$.

8. 1991 Census of Child Care Services Summary. Department of Human Services and Health. Commonwealth of Australia 1994. Australian Government Publishing Service, Canberra. ISBN 0644354801.

9. Australian Bureau of Statistics. 1991 Demography New South Wales. Commonwealth of Australia. Catalogue No 3311.1.

Commonwealth of Australia. Catalogue No 3311.1 .
10. Varrasso DA, Redlener I. Defining delayed immunisation. (Letter) 10. Varrasso DA, Redlener I. Defining delayed im
Pediatric Infectious Disease Journal 1992;11:897.

11. Dietz DJ, Zell ER, Stevenson J. Defining delayed immunisation. (Letter) Pediatric Infectious Disease Iournal 1993; 12(4):353-354.

\section{Childhood immunisation editorial}

$\checkmark$ Continued from page 112

or about age-specific susceptibility to the major vaccinepreventable diseases. Until this information is available, and is used to tailor the childhood (and adult) immunisation program, control of highly infectious diseases such as measles and pertussis is but a pipedream.
1. Australian Bureau of Statistics. Children's immunisation, Australia, April 1995. Canberra: ABS, 1996. Catalogue no. 4352.0.

2. Herceg A, Daley C, Schubert P, Hall R, Longbottom $H$. A populationbased survey of immunisation coverage in two-year-old children. Aust $J$ Public Health 1995; 19:645-470.

3. Ferson MJ, Christie D. True and false contraindications to pertussis 3. Ferson MJ, Christie D. True and false
vaccine. Med J Aust 1990; 153:568-569.

4. Rixon G, March L, Holt DA. Immunisation practices of general practitioners in metropolitan Sydney. Aust J Public Health 1994; $18: 258-260$

5. Burgess MA, Levy M, Alperstein G et al. 'On the spot' vaccination: does it work? I Paediatr Child Health 1996; 32:63-67. 